\title{
Artificial Intelligence and Its Role in Human Resource Management
}

Inayat Kalra

AMITY BUSINESS SCHOOL, AMITY UNIVERSITY (NOIDA),

To Cite this Article

Inayat Kalra, "Artificial Intelligence and Its Role in Human Resource Management", International Journal for Modern Trends in Science and Technology, 6(8): 310-317, 2020.

Article Info

Received on 28-July-2020, Revised on 12-August-2020, Accepted on 18-August-2020, Published on 26-August-2020.

\section{ABSTRACT}

The purpose of present research is to study the application of artificial intelligence in human resource management. Artificial intelligence in organisation technologies provide many opportunities in order to improve the functions of human resource management. For example: transactions, process of recruitment, selection and talent acquisition, reporting, accessing the policies and procedures, etc. Merging AI into Human resource functions would be highly beneficial in improving the overall employee experience. Employee experience is most important for employers in organisation to keep the employees engaged. With the help of Intelligent chat bots that are used to make fast and reliable interactions easily. With help of artificial intelligence. There will be more detailed focus on planning in the organisation by the HR people, thus this helps to evaluate data in more speedy manner than an average person. In return brings more attention to employers who were earlier not given a consideration or such people who were not even looking for work.

KEYWORDS: artificial intelligence, employee experience, employee engagement, chatbots, speedy and reliable interaction.

\section{INTRODUCTION}

\subsection{WHAT IS ARTIFICIAL INTELLIGENCE?}

From the development of machines, their ability to manage different tasks continued developing . The development of AI took place initially in year 1956 and continued to expand more following new ways.

AI is achieved by thorough study of the way a mind thinks and how we learn, decide, and work to tackle problems in organisation on the basis of this study for making of such intelligent systems.

A major thrust of AI is in the development of machine functions are linked with human intelligence, like reasoning, learning, and solving problem.

Thus, the 2 main goals of artificial intelligence are-
- To create expert systems

- To implement human intelligence in machines

\subsection{FUNCTIONS OF HRM WHERE AI IS USED}

Artificial intelligence (AI) have completely changed our life than ever before. thus it has effected us on these levels from ;

- The transformation of tedious, time-consuming tasks to;

- The augmentation of human capabilities and;

- The amplifying of functions performed by people .

Following are a few functions of HRM that shed a light on a promising integration of technology with the field: 


\section{AI RECRUITERS}

Artificial Intelligence for recruitment is an emerging category of the Human Resource technology which is designed to reduce or even remove some of the HR activities which are very time consuming for the management.

The talent acquisition team within a company is responsible for finding, acquiring, assessing and hiring candidates to fill up the roles that are required to fulfil the requirements of a project thereby achieving the goals of a company.

\section{II.ONBOARDING}

This is where Artificial Intelligence came. It decides the on-boarding process for every position. This ended up being very productive since new employees who experienced well-planned on-boarding programs that gave much higher retention rates than their colleagues who didn't grab the same opportunity.

\section{PERFORMANCE ANALYSIS}

It not only increases productivity yet in addition to identify the team members who show lack of engagement. A UK based company, Work Compass is already using artificial intelligence and machine learning to analyse the quality of yearly or monthly goals of employees. They claim that this lead to an $11.4 \%$ increase in employee productivity. They make proposals based on Artificial Intelligence calculations in order to monitor the performance throughout the year with formal reviews. Artificial Intelligence has made it easy by assigning weightage to each of employee's goals and mapping it with their performance all around the year.

\section{TRAINING AND DEVELOPMENT}

It is essential for the employees to continue learning also improving their professional skills due to so many technological changes happening around so frequently. Artificial Intelligence can happen, organise and coordinate the training members for its staff. The most common solution for this is Online courses and digital classrooms.

\section{EMPLOYEE DEVELOPMENT}

It helps AI professionals to evaluate data on various aspects like gender , and culture backgrounds, work ex, their educational qualifications etc companies which use AI have made the learning aspect as easy as watching a movie or playing games on play station .

\section{PERSONALISED}

EMPLOYEE

\section{EXPERIENCES}

Employee experience is most important for employers in organisation to keep the employees engaged. With the help of Intelligent chat bots that are used to make fast and reliable interactions easily. Virtual assistants to meet needs of workforce

Example - The officials of IBM examines how effectively Artificial intelligence technology can be put together into an employee's on - boarding program. IBM is planning to create a system that will answer a new employee's job related critical questions.

\section{EMPLOYEE RETENTION}

Below are some ways how $\mathrm{AI}$ can be used to improve employee experience and retention -

- Better work life balance

- Identifying opportunities for growth

- Improving productivity

VIII. ACCESSIBILITY TO HR TRANSACTION DATA

HR managers can access data of an employee with authorisation. Example - employee's job history, performance rating or team information. Conversational artificial intelligence can also be a key performance indicator information. Example the number of employees present, the top performers, pending transaction requests, etc.

\section{HUMAN ANALYTICS}

Since many years, companies have been gathering data to find a way to predict future behaviour. HR teams have a lot to do - tracking data, analysing, managing and protecting. Artificial intelligence plays a greater role in HR to support people .

\section{COGNITIVE-SUPPORTING}

DECISION MAKING

Cognitive engines could help employees in arriving at day-to-day decisions in the workplace. Usually, these tasks are done by the HR team members.

\subsection{PRACTICAL APPLICATIONS OF BUSINESS $\mathrm{AI}$}

a) COGNITIVELY COMPLEX TASKS - AI can also help with complex cognitive tasks. Suppose we want to predict the selling price of a house, given 
some information about it (number of rooms, location, and more). We can't solve the problem by looking at descriptive tables or graphs because the task requires complex cognition. An experienced realtor might be able to process this information and estimate the price, but this approach has two limitations. First, need relevant experience in order to use this information accurately. Second, even if have the experience, can't scale the process. With the right data and training, AI can also be used to handle cognitively simple tasks (like seeing things in an image) in more complex scenarios - for example, using computer vision to find malignant tumor sites or language processing for translation.

\section{b) CUSTOMISED CUSTOMER EXPERIENCE} -When it comes to applying these capabilities in a business setting, the first example is always personalized customer experience. A customer's actions and interests can be used to tailor their experience while they are using the product. For example, Netflix uses movies you previously watched, along with other data, to recommend movies. It also uses this information to decide what new content to create. Machine learning is used for this kind of service, because it's very difficult to customize recommendations for each of the different users.

c) OPTIMIZE INTERNAL PROCESSES - These tasks typically don't involve creativity or complex problem-solving, but they are time consuming for your team. This approach offers several advantages. First, you free up valuable time for your team to work on other things, like actually selling properties. Second, with the right data, AI can make great predictions for a variety of different inputs. Third, this solution allows you to respond to customers in seconds instead of making them wait for your human team to come up with a response.

d) AID IN DECISION MAKING - For example, let's say a company is figuring out its budget for the next year. Machine learning can be used to forecast expenses, instead of just making an estimate off of last year's values. Or let's say, the company wants to know whether to invest in a new market. It can use models to process tweets about that market and analyse public sentiment. This one signal alone won't determine its decision, and it shouldn't, but it can help get the company get there. Applying AI in this way is particularly useful when the decision is very sensitive or complex.

\subsection{APPLICATIONS OF AI IN THE MARKET}

AI is not the future anymore it is today and happening be it From candidate acquisition to scanning resumes, or to improve engagement among workforce in organisation and answering real-time questions at large. AI has a lot of potential to bring revolution among HR Industry. Today, employers in big companies like Google, Cisco, PepsiCo, Amazon are conducting tests and adopting data-driven and predictive tools for betterment of the hiring process.

Following are some of the very popular examples of A.I. being used today-

\section{SIRI}

Today we all are aware of Apple's personal assistant, SIRI . Hence it is a computer activated friendly voice which we can interact with and ask general questions about weather, sports etc. it help us giving us directions to places, remind us important meetings and understand our language, questions and requests.

\section{ALEXA}

Amazone's Alexa almost took most of the world and its rise to become the smart phone's hub. However, its convenience and its uncanny capacity to give discourse from anyplace in the room has made it a progressive item that can assist us with scouring the web for data, shop, plan arrangements, set cautions and a million different things, yet in addition help power our brilliant home .

\section{AMAZON.COM}

This has been now in presence for long now which can make a huge amount of money online. It can easily predict the customers demand online through our behaviour.

\section{NETFLIX}

It helps to provides highly predictive technology entirely based on customer's reactions to films. It predicts on the basis of our search regarding the past films and AI helps it to grow more smarter.

\section{TESLA}

It is famous for its self driven cars and more add on features which make it a exclusive and its high technology has helped it to received a lot of fame and its one of the best cars till now . 


\subsection{CHALLENGES IN ADOPTING AI IN ORGANISATION}

- Inequality: By utilizing man-made reasoning, an organization definitely quits depending on its human workforce, and this implies the incomes go to a less people because of this headway. Therefore, people who got proprietorship in AI-driven organizations get the chance to make all the cash in the long run.

- Artificial stupidity: Knowledge originates from realizing whether it's a human or any machine. System for the most part have a phase in where they figure out how to identify the correct examples and act in like manner based on their info.

- Biases: How can biasness be eliminated? here are $100 \%$ odds of biasness since the AI innovation is made by people itself and people are extremely critical essentially. Whenever ideal for social advancement, computerized reasoning can be a quickening agent for positive change.

- Security: The more remarkable any innovation turns into, the more it tends to be utilized for bounty number of reasons. This applies not exclusively to robots which are delivered to supplant people, yet to AI frameworks that can cause harm on the off chance that they are utilized devilishly

1.6 BARRIERS TO ADOPTING AI TECHNOLOGY

- Talent gap: it can be expensive and hard to find properly educated or skilled people.

- Concern over privacy: Proper confidential HR data must be evaluated securely and available only to the concerned people

- Ongoing maintenance: AI deep learning and regular review and updates. Bias are only learned from software Therefore, a basic knowledge the way the technology works, and awareness is important.

- Integration capabilities: Availability of data and a vast amount of data that is highly important for any AI software to human intelligence. So, ensuring there is a vast database of resumes and other related sets of information readily available is quite difficult to manage

\section{Methodology}

RESEARCH-: Research is defined as a careful consideration of study regarding a particular concern or a problem using scientific methods. It is basically a systematic inquiry to describe, explain, predict and control the observed phenomenon.
RESEARCH METHODOLOGY - Research methodology is the specific procedures or techniques used to identify, select, process, and analyse information about a topic. It helps to evaluate overall reliability of the study and answer questions like How was the data collected or generated? How was it analysed?

- RESEARCH DESIGN - it is blueprint of research project and depends upon strategy of research.

METHODOLOGY - The main aim of this report was to gather all sorts of information about Artificial Intelligence and its applications. The research design that was adopted to achieve this objective was Qualitative Research Design further categorised into Exploratory Research.

QUALITATIVE RESEARCH DESIGN - subjective research is a procedure that is about request, that helps inside and out comprehension of the issues or issues in their normal settings. This is a non-factual research strategy.

- EXPLORATORY RESEARCH - As the name suggests, exploratory research is conducted to explore the research questions and may or may not offer a final conclusion to the research. This type of research was conducted because the ideas and thoughts are key as it is primarily dependent on their personal view about a particular topic.

\section{DATA COLLECTION METHODS-:}

Data collection plays a important role in the statistical analysis. In research, there are different methods used to gather information, all of which fall into two categories, i.e. primary data, and secondary data..

\section{FINDINGS FROM THE STUDY :-}

My topic of research was such which require secondary data i.e case study which helped me gain more knowledge about the topic. For SECONDARY DATA, I did more research from some case studies of few known companies, collected information from the Business Magazines, from articles and some research papers from the internet.

\section{OBJECTIVES-:}

- To study about the concept of Artificial Intelligence 
- To gather information about the applications of AI in HRM and other fields

- To get some information about the applications of $\mathrm{AI}$ in the market

- To get some insights on the challenges faced by companies due to AI

- To study about the future scope of AI

\section{LITERATURE REVIEW}

Jarrahi (August 2017), said that Artificial insight (AI) has infiltrated numerous authoritative procedures, bringing about a developing apprehension that shrewd machines will before long supplant numerous people in dynamic. With a more prominent computational data preparing limit and a scientific methodology, AI can broaden people's comprehension while tending to multifaceted nature, though people can at present offer a progressively all encompassing, instinctive methodology in managing vulnerability and dubiousness in hierarchical dynamic. This reason reflects the possibility of insight growth, which expresses that AI frameworks ought to be planned with the goal of increasing, not supplanting, human commitments that are required to be.

Elliot (June 2017), talked about the challenge between human robot association and man-made consciousness in numerous respects, which included dynamic, somewhat obscure conditions that were not initially intended for robots; Discussing every one of these capacities, presents working usage, and shows how they consolidate in a sound and unique deliberative engineering for human-robot connection. Bolstered by trial results, he in the end indicated how express information the executives, both emblematic and geometric, ends up being instrumental to more extravagant and increasingly regular human-robot communications by pushing for unavoidable, human-level semantics inside the robot's deliberative framework.

Holtel (2016) Machines with exceptionally advanced mental skills will flip around the information work in each organization division, be it advertising, HR, innovative work, client assistance, or the even the top managerial staff. To begin with, organizations must include every important partner at the underlying phase of sending on the grounds that the effect of man-made consciousness is expansive. Second, organizations must scrutinize their given worth framework since it intently resounds with the capacities of man-made brainpower machines. Third, organizations must direct controlled tests, since "partition and rule" don't work any longer to deal with machines that emulate human reasoning

Yawalkar (2019), in his research paper, it helps to enter into departments like finance, marketing and human resource. This study has concluded that role of artificial intelligence and understand the challenges in the industry the main objective of the study was of handling the recruitment process , hiring, and analyzing the data, collecting the data and also lowering down the workload in the organisation and enriching the efficiency of workplace.

Matsa (2019), in his paper AI can be used as a tool which can help to improve the productivity and help in increasing the performance. Artificial intelligence uses certain Algorithms and also where machines can show behaviour by human beings . it has an Important role in HRM because it uses chatbot and also important in process like Recruitment, training and development, selection and etc . it also helps in providing various Services to employees based upon leave request and details, granting of leaves for vacation.

Lemaignan (2017), in this research paper has talked about the Human-robot interaction (HRI) speaks to a test for AI. Despite the fact that each work done by people genuinely, can done through AI. In any case, enthusiastic knowledge isn't there for AI. As this is the significant downside of human robot cooperation become basic. Robots can just do the things which are pre-educated to them. They can't change their activities by their own as they are constrained by people. It is a troublesome errand to force the autonomous programming modules, uniquely it isn't just a specialized test, however it is additionally a structural test.

Wislow (2017), in this research paper has talked about the role of AI In the title of top approaches to utilize AI in HR it was unmistakably expressed that AI is Reshaping the way that organizations deal with their work power and make the arrangements which builds efficiency and representative commitment as a rule. Ability obtaining is fundamental significant things, we can evacuate huge amounts of unpleasant and repetitive work from $\mathrm{hr}$ supervisors to be specific ability securing programming can output, peruse and assess 
candidates and rapidly disposes of $75 \%$ of them from the enlisting procedure. AI can design, sort out and can give such huge numbers of preparing projects to the recently joined representatives through online courses and computerized study halls. Simulated intelligence can predict the necessities of representatives then maintenance will be more for the representatives in the association it has a significant job in the association since work is impossible physically so with the assistance of man-made brainpower the work will be done without any problem.

Bersin (2018), it obviously shows that AI is very utilized in the majority of the zones of the board and furthermore about the dangers that will happen when it isn't utilized appropriately .AI are human made machines which are constrained by people dependent on the guidelines given by people .The frameworks with calculations and some learning instruments are utilized in AI since they have the ability to investigate a huge number of data and they are quick not normal for people. These frameworks encouraged us to see all the potential results for any issue and gives choices and causes us to pick the best arrangement. A portion of the regions that can get best outcomes by utilizing $\mathrm{AI}$ in $\mathrm{HR}$ are as per the following the employing supervisors might not be right while choosing the correct individual for the correct activity however frameworks with calculations looks at profile of competitors and pick the best appropriate individual.

Peter (2018), In the paper obviously shows that in close to coming future AI will get an extraordinary change the method of actualizing HR rehearses with the usage of ai in organisation without any doubt a few occupations might be influenced however as a general rule it raises the efficiency of an association albeit a portion of the western organizations are fruitful in incorporating AI with some HR rehearses and got beneficial and others are as yet depending on the cost perspectives and out of all the hr rehearses enlistment is the best capacity in coordinating with AI from sourcing and screening the certified candidates lastly it is the obligation of the administrations and the particular associations to reshape ability.

Srivastava (2018) , conducted a research AI assumes a significant job in HR the board it chiefly help us in labour arranging and profitability the executives really it is hard to break down the exhibition of a worker's physically so by utilizing tends to be done consequently and also enlistment turns out to be simple like most extreme time which is spend by the HR director on enrolment just so to diminish time this AI encourages us a great deal it is possible that it might be for recruiting in choice which are taken by AI will be better than the choices representatives or authorities through AI there will be no separation just as the choices of the pay will be done here by utilizing genuinely complex calculations altogether AI there will be better advancement in each association.

Shella M LC Govern (2018), In the paper AI is an apparatus which can be prepared so that people can do. As to AI in HR it lessens the human work and it will spare financial plan likewise and through this AI just approved individual can see all the information yet the pariahs can't see all the insights about to organization. By the utilization of $\mathrm{AI}$ it for the most part diminishes the HR assignments and dynamic will turn out to be simple with respect to various undertakings. New representatives don't have the foggiest idea where to proceed to contact in the associations this AI will help them by addressing inquiries of workers through chatbot. Supervisor can see the data of a worker in a made sure about manner.AI is an AI ability and it utilizes regular language preparing to think about representative and regardless of whether worker need to apply for a leave then this chatbot will show you the bit of leaves accessible and on that day is anybody decided on leave it will break down all the information and gives clear arrangement. The primary favourable position of this chatbot arrangement is that it very well may be open anyplace whenever. The arrangements will be imparted through secure web or intranet convention. By utilizing AI it gives us genuine advantages and improve the advancement procedure of an organization. It ought to be seen that the actualized AI arrangement should give right reaction consistently it ought to be refreshed and upkeep of rationale accurately.

Gale (2019), In the paper AI is rising and $\mathrm{hr}$ administrators ought to be set up of how to utilize this innovation all the future work will be finished by AI so IBM,PWC and deloitte they are done overviews on effect of AI on hr most recent year and a half and it is cleared that organizations need to actualize AI yet they doesn't $t$ not comprises representatives with appropriate authority to make 
it IBM anticipate that 120 million laborers on the planet's 10 biggest financial aspects need to offer preparing to laborers in regards to $\mathrm{AI}$ and if the organizations didn't begin serious edge in regards to improvement regardless of whether organization need to build up AI however representatives don't demonstrate enthusiasm to pull it off. $80 \%$ of representatives in us and uk accept that having AI aptitudes will be valuable to them to get advantages to organization and $42 \%$ said that they are not that they are not accepting that their HR divisions can execute it. HRD assumes a significant job in each association so it needs innovations like AI to be progressively serious in the zones changing business condition and this beginnings with change in culture where subtleties used to take choices so directors and the workers of HR need to think .

Bharadwaj (2018), in his paper unmistakably expressed that any association will get a lot of resumes out which just $10 \%$ are pertinent. From recruiting to worker commitment, computerized reasoning is changing the route because of the appearance of AI upheld frameworks. This procedure is currently taken over by programming search calculation that can effectively validate the couple of individuals coordinating your necessities from a heap of inaccurate applications. Man-made brainpower is re-forming and each circle in life including HR the executives It can be joined in process like boarding, execution, survey, criticism, preparing, separated from ability. Consequently, it permits HR chief more prominent time and vitality to concentrate on tutoring and rousing representatives. HR office is exceptionally profited with the AI supporting framework.

Dr Nunn (2018), , at present AI turned out to be generally significant in pretty much every industry it is the fantasy of each HR administrator to utilize AI in their association predominantly mechanizes correspondence with competitors the two significant things in AI it for the most part takes out biasness while choosing the applicants and expanding effectiveness of the up-and-comers AI for the most part helps in screening process it down up-and-comers profile and interface with them and take a choice of choosing the correct up-and-comers it fundamentally decreases the weight of work and the principle spotlight will be on the top up-and-comes AI can do facial acknowledgment and furthermore it leads the meetings basing upon instruction levels and their capacity and so on., through AI the holes can be filled in HR office like primarily in regards to preparing and advancement that implies naturally investigating the aptitudes and prerequisites to satisfied by representatives it chiefly associated organization's vision and to accomplish the objectives .AI begins from enrolment and at last remuneration level it principally utilized so without a doubt AI will be a developing innovation in each association.

Dr Jain (2018), In this paper HRM and AI shows that $\mathrm{hr}$ in the past used to concentrate on the board of representatives in association yet now gradually it moved its concentration to construct an association that adjusts to the much of the time changing condition since change in condition will impact the association. The AI is reproducing the association in this computerized world so the HR ought to rethink as needs be. Computer based intelligence is a useful show by machines in close relationship with insight of humans.HR should prepare the representatives about the new advancements all together for better future. Straightforwardness has gotten standard in the realm of HR, representatives can look at their pay rates against those of comparative occupations utilizing a portion of the apparatuses like compensation.

\section{IV.DISCUSSION}

This study is about the various applications of Artificial Intelligence in the field of Human Resource Management. This research project has helped me gain a lot of knowledge about the advancement in technologies these days and how we people are trying to adapt and adopt these technologies in our personal as well as professional and corporate lives. Human resource has an immense opportunity to lead the transformation to an enterprise. The HR leaders who learn new technologies and new ways of working and who explore through constant reinvention, will be strongly having an impact on the employee experience and the business results. Today, HR's focus has shifted towards building the organisation. Companies are now hiring young digital savvy employees who can do things by themselves and share information in a very transparent manner. They want a digital experience at work - productivity and empowerment and HR is very well expected to fulfil these expectations. In future, HR needs to embrace new technologies. They must take advantage of the 
tech disruption to save time and energy for better purposes. The HR function could then be able to rise much above than what mere machines usually do. Numerous associations are as of now observing the abilities of AI, utilizing these points of interest to improve human knowledge and increase genuine incentive from their information. As there is expanding proof exhibiting the advantages of insightful frameworks, more leaders in the meeting room are increasing a superior comprehension of what AI can truly offer.

POSITIVE IMPACT ON FUTURE :- The future of Artificial intelligence is hazy. But going by the bounds of progress AI has been making, it is clear AI will permeate every sphere of our life. Man-made brainpower is changing our lives at home and at work. At home, you might be one of the 1.8 million individuals who utilize Amazon's Alexa to control the lights, open your vehicle, and get the most recent stock statements for the organizations in your portfolio. $80 \%$ of respondents in the EY study said it was the absence of these abilities that was the greatest test while utilizing AI programs. Computerized decisioning will be answerable for undertakings, for example, favouring advances, choosing whether a client ought to be on-boarded or recognizing defilement and money related wrong. Organisations will benefit from an increase in productivity result in large revenue

\section{REFERENCES}

[1] [Vishal Marria. (2019). The Future of Artificial Intelligence In The Workplace. Retrieved ., from https://www.forbes.com/sites/vishalmarria/2019/01/11 /the-future-of-artificial-

[2] Prasanna Tambe, Peter Cappelli, Valery Yakubovich. (2018). Artificial intelligence in human resources management: Challenges and a path forward . Retrieved ., from

https://www.researchgate.net/publication/328798021_A rtificial_Intelligence_in_Human_Resources_Management_C hallenges_and_a_Path_Forward

[3] Vibhuthi Viswanathan. (2018). Future Scope of Artificial Intelligence. Retrieved ., from https://www.springpeople.com/blog/future-scope-of-artifi cial-intelligence/

[4] Martin fr. (2019). EMPLOYERS ARE NOW USING ARTIFICIAL INTELLIGENCE TO STOP BIAS IN HIRING. Retrieved ., from https://www.analyticsindiamag.com/employers-are-using -ai-stop-bias-hiring/

[5] Sam Shead. (2016). Investors are backing more AI start-ups than ever before. Retrieved ., from https://www.weforum.org/agenda/2016/06/investors-ar e-backing-more-

[6] Adi Gaskell. (2018). Can AI Help With Performance Management?.Retrieved ., from AI-startups-than-ever before https://dzone.com/articles/can-ai-help-with-
[7] Neotys. (2018, 5 March). 4 EMERGING TRENDS IN AI \& LOAD TESTING. [Weblog]. Retrieved ., from https://www.neotys.com/blog/emerging-trends-ai/

[8] Cbiinsights. (2017). AI Will Put 10 Million Jobs At High Risk - More Than Were Eliminated By The Great Recession. Retrieved ., from https:// https://www.irjet.net/archives/V6/i8/IRJET-V6I8226.pdf

[9] www.cbinsights.com/research/jobs-automation-artificial-i ntelligence-risk/ 